\title{
DEVELOPING INTERACTIONS IN AUGMENTED MATERIALITY: AN ENHANCEMENT METHOD BASED ON RGB-D SEGMENTATION
}

\author{
Assist.Prof.Dr. Selcuk ARTUT \\ Sabancı University, İstanbul \\ sartut@sabanciuniv.edu \\ https://orcid.org/0000-0001-7323-7234
}

\begin{abstract}
Knowledge and understanding of how Augmented Reality develops an illusion of an alternative reality that needs to be critically considered with philosophical and technical points of view. Researchers have been investigating on exploring different techniques to generate enhanced experiences for the users. In this article, the technological reality scenarios embodied within several Augmented Reality techniques are explored and a classification scheme is proposed in detail. Additionally, for the purposes of enhancing the cohesion of an augmented visual content to the actuality, an Augmented Reality software based on a segmentation using RGB-D camera system that handles the occlusion problem will also be explained and an enhancement method will be discussed.
\end{abstract}

Keywords: augmented reality, perception of reality, occlusion problem, depth camera, segmentation

\section{ARTIRILMIȘ GERÇEKLIK ETKİLEȘIMLERINIIN GELISTTIRILMESİ: RGB-D SEGMENTASYONUNA DAYALI BİR YÖNTEM}

\section{ÖZ}

Artırılmış Gerçeklik, içerdiği alternatif gerçeklik yanılsamaları ile birlikte ele alındığında, konunun felsefi ve teknik bakış açılarıyla birlikte tartışılması gerekliliği ortaya çıkmaktadır. Günümüzde araştırmacılar, zenginleştirilmiş kullanıcı deneyimleri yaratabilmek için farklı biçimlerde araştırma yöntemleri geliştirmektedirler. Bu makalede, çeşitli Artırılmış Gerçeklik teknikleri içinde yer alan teknolojik gerçeklik senaryoları araştırılmış ve ayrıntılı bir sınıflandırma şeması önerilmiştir. Ek olarak, artırılmış görsel içeriğin gerçekliğe uyumunu artırmak amacıyla, ön arka ilişkilerine dayalı üst üste oturma problemini ele alan ve RGB-D kamera sistemini kullanan segmentasyona dayalı bir Artırılmış Gerçeklik yazılımı da açıklanmaktadır.

Anahtar Kelimeler: artırılmış gerçeklik, gerçeklik algısı, öne geçme problemi, derinlik kamerası, segmentasyon

\section{INTRODUCTION}

Our eyes intake countless images and it is increasingly difficult to keep from being exposed to such visual bombardments including the spread of Augmented Reality implications. Our fields of view that allow us to observe reality are about to go through a rapid technological evolution. The reflecting and reflective surfaces that have become a daily part of our lives in new lifestyles dictated to us by present technology enable us to interpret and perceive differently the reality we witness in the real world. On top of the reflecting and reflective surfaces, the transparent surfaces with their ever-evolving technology can make much more effective manipulations in our visual perceptions with techniques like Augmented Reality. Things we see rapidly cease to be what we observe and various 
individualizations that create differences are observed in the visual perceptions of individuals. Although the added realities (created in our individualized visual perception fields) are products of a virtual world, these virtual objects (created in our metamorphosed visual perception analyses without their material features) trivialize the measure of the reality that we construct in our minds due to their frequent practical implications.

Our naked eye enables us to observe, interpret, and perceive what is happening in the world around us. Despite all the forefront technological developments, there has been no change in the physiological structure of the eye. However; this technological perception of reality which human witnesses with his / her very own eye, has been exposed to new philosophical questionings. Some of these concerns are based on the artificial reality-simulations such as simultaneous Virtual Reality and Augmented Reality as well as the developments in manipulation techniques applied in recording and recorded images. It may become difficult to believe the things that our eyes will witness as technology continues developing.

According to G.K. Pal and Pravati Pal (2001), a healthy human eye can see lights between nearly 400 and $700 \mathrm{~nm}$ in wavelength. Considering the presupposition that light shows wave property, according to the data from these measurements, a human eye cannot see lights outside of certain vibration rates. However the determined wavelength range differs from living beings to living beings and some creatures can even see infrared and ultraviolet spectrums.

Throughout history, the reality of the invisible was always thought to be of speculation. In order to prove something's existence, it is obliged to be perceived similarly by a population of people. However, efforts such as illusions, whose reality is just made-up do still exist as abnormalities in the perception of reality even though everyone sees in the same way. Human nature, though enjoying pattern and order, has always been the suspect of abnormalities, defining them as unusual. While some authorities tried to deny magic and wizardry, some other communities preferred to use these activities as harmless entertainment tools.

Figure 1. Brunelleschi's Mirror Apparatus

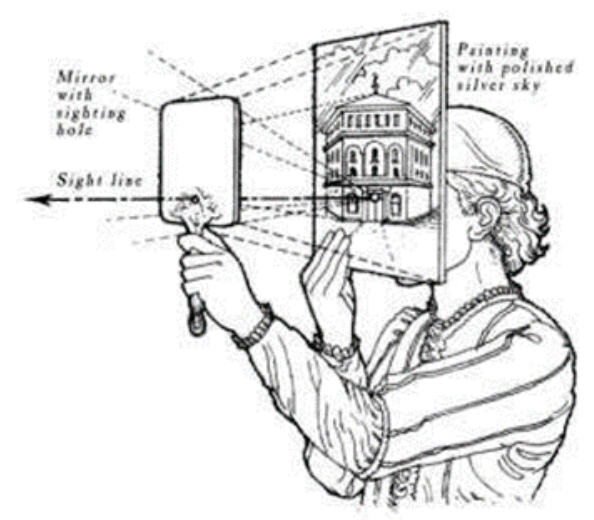

(Source: http://info.aia.org)

Optics are based on the linearity presupposition and benefited from Euclidean axioms while developing in time. Another scientist accepting linearity as a perspective and proposing a model on how humans describe the world, is Filippo Brunelleschi. Brunelleschi asserts the idea of Linear Perspective and shows what kind of a method is to be used in order to turn the three-dimensional world we see into a two-dimensional form rather than producing a difference in our visual habits. In order to prove his Linear Perspective idea, Brunelleschi turned a front elevation drawing of the Florentine Baptistry of San Giovanni into a canvas by using the Camera Obscura method (Tsuji 1990). Looking through a hole the size of a lentil, the viewer can see a baptistery image stabilized on a twodimensional surface thanks to the mirror standing just opposite the drawing and held by him.

Research Article - Submit Date: 15.11.2018, Acceptance Date: 15.12.2018 
Alongside of the image observed in the mirror, mobile and stable objects of the real world, such as clouds in the sky or people portrayed around the building in the two-dimensional image, create another reality environment with the two-dimensional surface. The optical test held by Brunelleschi in the 14th century can be seen as the pioneer of the applications in which today's screen and view of reality dually perceived.

The mirror used as the screen in the aforementioned test started to be used as reflective and reflecting surfaces recently. We are currently working with applications in which reality and virtuality engage. When we put the reality and virtuality into two different poles, Milgram et al. (1994) explained that these realities or virtualities leave a mark in our perception with the Mixed Reality notion.

Fig. 2: Reality-Virtuality Continuum (Milgram et al. 1994)

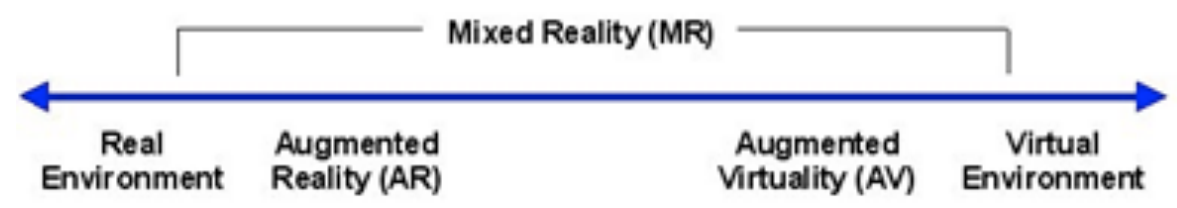

Milgram et al. defines Augmented Reality as superimposition of the virtual objects upon the real world, thus it stands not as an alternative to replace the reality but to supplement and augment the observed reality. Considering Augmented Reality applications of the past, the Pepper's Ghost Effect (Sidharta, R., Hiyama, A., Tanikawa, T., \& Hirose, M 2006, Brooker, J. 2007, Kuhn, Amlani \& Rensink 2008) becoming popular again recently under the light of technological developments is thought as one of the pioneers of this field. John Henry Pepper used Pepper's Ghost visual effect as an illusion method in the 17th century in order to put the ghost characters into the stage simultaneously with the players. By setting objects at a specific angle, on a plane invisible to the audience, the objects themselves became visible and impressed viewers as if they were virtually existing on the stage.

Fig. 3: Pepper's Ghost Illusion (Schweitzer, M., Zerdy, J., 2014)

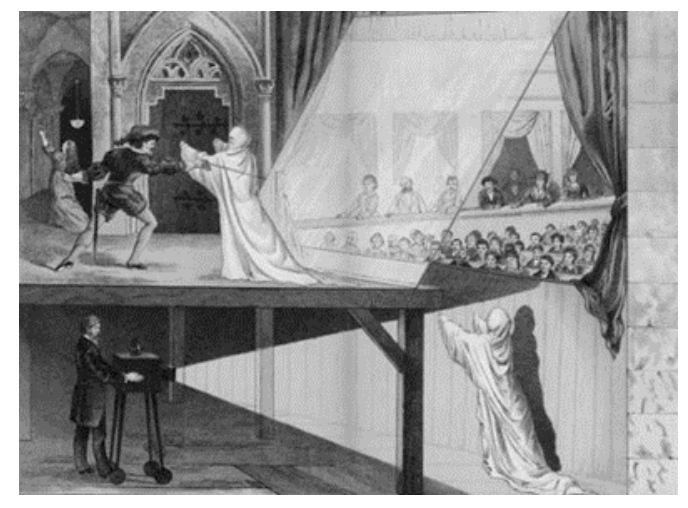

Today Pepper's Ghost illusion method is applied more successfully thanks to certain technological developments. Through the denser lights of reflective projectors and enhancements applied on the reflecting material's surface, this illusion method became commonly used in popular applications as well. In 2012, at the Coachella Valley Music and Arts Festival, using Pepper's Ghost effect, the previously recorded video of Tupac Shakur's (famous Hip hop singer who lost his life in 1996) was reflected onto stage with another hip hop singer, Snoop Dog, making the performance as if live. This concert using illusion can be considered as a sample of mixed reality.

Although there had been many movies such as Song of the South (1946), Who Framed Roger Rabbit (1988) in which similar illusions had been applied successfully by using visual effect methods, this simultaneously performed concert experience in Coachella Festival had a much more powerful effect

Research Article - Submit Date: 15.11.2018, Acceptance Date: 15.12.2018 
on audience the audience in terms of mixed reality. That is because both a person who is not alive and another one who is alive stood together on a concert stage in front of the audience at the same time as well as performing a real concert performance together.

As the developments in technology towards changing our reality perception are investigated; besides the complicated constructions, Augmented Reality has come to be included in human's daily life with some practical implications (Azuma 1997, Kaufmann and Schmalstieg 2003, Kamphuis et al. 2014). In this article, while mentioning the differences of the dimensions resulted by Augmented Reality, other applications discussing metamorphosing reality perception are emphasized as well. What kind of applications Augmented Reality, becoming an interesting subject of visual illusion, turned or to be turned into in terms of performing arts is also included in this article's field of interest.

\section{REALITIES BEYOND OUR SIGHTS}

Due to the fact that the human eye can only display sensitivity to a light which exists in a determined wavelength, other light events cannot be seen with the naked eye. This situation brings an opportunity to enhance the image process techniques in the field of computer vision. Some infrared technologies were used recently in order to distinguish the objects in field of image processing in front of the camera and to identify their movements. Today, depth cameras equipped with motion recognition features such as Kinect, Xtio, and Creative Senz 3D, process the images with the infrared detector cameras by reflecting the invisible infrared rays on the surfaces. With this method, these infrared rays produce what we cannot see with the naked eye, forming images and figures that we do not distinguish in our field of view.

Technology turned the invisible into visible and enabled a number of applications to be developed. In addition to infrared technologies, thermal photography, x-ray and so many others with rays are invisible in the naked eye, are used in many fields of life such as restoration of art objects, photography, wireless communication, medical applications, and astronomy.

Through the techniques such as infrared, thermal photography, and x-ray used in investigation and restoration of some painted works of art, many of the drawing processes of a painting are now visible and it is also now possible to gather various information about the painting. One of the most spectacular discoveries of this subject was revealed after the X-ray studies on Picasso's 'The Old Guitarist - 1903'. As a result of the analysis, a woman with a bending head in the table can be seen. It is a mystery as to why to the reason this hidden woman figure, is not portrayed in the piece of art and there is only a composition of a man playing guitar in the painting.

In 1895 with the discovery of X-Ray by Wilhelm Conrad Röntgen, a new era began, not only about the human body's internal structure, but also the internal makeup of many other materials. Emerging at the beginning of the twentieth century, this development reinforced the ecole of defining the invisible, pioneered by the art movements such as Cubism and Futurism with the brand new discovery of technology. Moreover, artists of the era such as Picabia, Kupka, and Duchamp made x-ray the subject of their paintings (Henderson 1988). New reality strains witnessed by X-Ray played a big role in broadening new horizons.

Various technological developments in field of screening offer an invisible reality to humanity with brand new methods. The realities without human effect, also defined as true realities, have changed with a set of technological discoveries and different approaches of art. A new meta-reality state has emerged by metamorphosing over time.

$$
\text { Actual Real } \rightarrow\{\text { Science }+ \text { Art }\} \rightarrow \text { Technological Real }
$$


While the natural reality sometimes protects its nature inside of the technological reality, it is sometimes suppressed and covered. For instance; the natural reality world in the Virtual Reality is in a way replaced by another world produced with Computer Graphics. However; the human body is not completely satisfied with reality although its visual perception is covered with Virtual Reality environments. That is because even though the main source of our perception enabling us to watch the reality is our eyes, they are not the only force causing us to live in reality. Some other factors such as touching, talking, balancing and moving, provide our existence in the environment we exist in. For this reason, Virtual Reality is not the actual reality, on the contrary, it is the reality, which can be observed in the actual world. (Yoh, 2001).

\section{CATEGORIES OF AUGMENTED REALITY EXPERIENCES}

In contrast to Virtual Reality experiences, Augmented Reality experiences encompass physical objects of actuality in their embodied environments with various representations. The notion of Mixed Real is categorized with the user interfaces in the categorization conducted by Milgram et al representing reality and fictionalized reality. Nevertheless; Augmented Reality was improved over time and formed its own sub-categories. Augmented Reality experiences can be grouped into the three following categories.

\section{Transparent Augmented Reality}

In this form of experience, users are exposed to a visual representation where objects of augmentation are exposed on a transparent surface such as a clear window or a haptic eyeglass with a relatively smaller projection window. An example of a clear, or see-through Augmented Reality experience is the aforementioned, Peppers Ghost effect commonly known as Holographic Projection. Peppers Ghost method which was used as a visual effect at the end of the nineteenth century was revisited again recently with the developments in projection technology and the effect has become popular again. On the other hand, one can perform this Augmented Reality experience by wearing specially produced haptic devices, Augmented Reality glasses. The experience is special for the individual because the image only occurs in the visual area of person wearing the glasses. Since there is a need for using extra device, there is an intervention to the actuality of the individual. That is why, this Augmented Reality enables the individual to experience an Augmented Realism whose reality questioning is neglected, because of the characteristically produced devices. For example; thanks to the AR glasses in the automobile industry, extra information via glasses is presented to the technical staff inspecting the parts of the automobile and it is aimed to enrich existing information. The experiencer can sustain his/her occupation in a pragmatist manner and salubriously without questioning the reality of the augmented information and visual images in a screening area.

\section{Projected Augmented Reality}

In this method, through the projection on objects having physical volume and images occurring on surfaces create the augmented fictional reality thanks to the obtained dimensional sense. Since Augmented Reality experience doesn't require a device to wear, it is possible for many people to experience at the same time as well as it is quite easy to be involved in the environment. Although it resembles the traditional projection methods in terms of these properties, considering volumetrical properties of the projection surface, with the specially produced and reflected images, the Projected Augmented Reality method reinforces the reality perception in the audience through 3D perception.

The Projected Augmented Reality technique is used in many applications of art and design. Projection mapping applied in the projects such as Rowe's (2014) Glowing, Pathfinder Bugs, Pest Control, Infestation and Living Timeline on physiological objects states that the participants are highly involved in the more effectively fictionalized reality. 


\section{Framed Augmented Reality}

Widely known as Window on World, this type of Augmented Reality is viewed by a camera on a surface and the augmented substance shows compliance with visuals such as light conditions and perception of perspective. Sample applications regarding this field have developed rapidly especially with the common use of mobile devices and could reach wider masses with practical uses aiming to meet daily needs. A participant experiencing at Mobile Framed Augmented Reality can control the area he/she is actively observing with the use of a mobile device. Even though it is similar to the headset glass applications in transparent augmented reality, the formed environment can only be seen from one monitor here.

The same situation can also be seen in Public Framed Augmented Reality applications. Participants witnessing an existing framed AR system looking at the monitor, without using any device, can still have the experience. The National Geography Channel's advertising activity in 2011 serves as an example for Public Framed Augmented Reality.

Fig. 4: National Geography Channel Advertising Activity (2011)

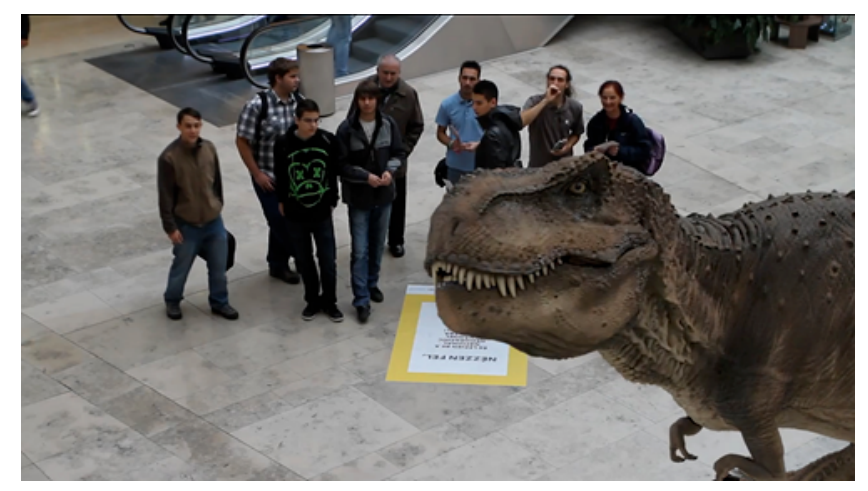

In this activity, thanks to the display system and position of the camera in the environment, some of the $3 \mathrm{D}$ animations are augmented in the giant screen participants are looking at. With the condition that participants shall not pass the graphically bordered frame of view, animations are formed in accordance with the perspective at the depth z. However; augmented visual equipment in such kind of applications do not stay behind the people in the environment, rather they stay on top of the screen. This limits the movement ability of the participant. And thus, this activity turns into a play-alone activity rather than a play-along with interaction. Participants may ignore the occlusion problem by being obliged to adapt themselves to the movements of the augmented objects.

Table 1. Categories of Augmented Reality Experience

\begin{tabular}{|c|c|c|c|c|}
\hline Method & Transparent AR & & Projected AR & Framed AR \\
\hline \multirow[t]{2}{*}{ Exposition } & Projection/ & \multirow{2}{*}{$\begin{array}{l}\text { Projection on } \\
\text { Haptic Devices }\end{array}$} & Projection on & Screens \\
\hline & $\begin{array}{l}\text { Reflection on } \\
\text { Surfaces }\end{array}$ & & 3D Bodies & \\
\hline Experience & Shared & Individual & Shared & Shared \\
\hline
\end{tabular}




\section{Realistic Augmented Reality}

Due to the fact that Augmented Reality is rendered as real-time, augmented images have to adapt to a dynamic and ever-changing environment. The first priority in this aim is to settle the augmented images in compliance with the environment's perspective and 3D reality perception of the person. The preferred method in many applied techniques is to provide an image of the environment with geometrical transformations of the augmented images. Nevertheless; in addition to the geometrical relation, some variants such as color, tone, density, angle of the source of light cause some changes in visual perceptions of the objects. If these mentioned variants can be applied to the augmented objects simultaneously, it will considerably increase the proximity of the object(s) to the real image.

For instance; it would be possible to create a synchronous and simultaneous photomontage for an augmented choreography to be produced for performing arts (on stage) when the information of how to use light on the interior is simulated in a 3D environment. On the other hand, in environments whose physical conditions cannot be under control, integration of the augmented object into the image screen can be enhanced if the light conditions are recreated for a 3D environment by the sensors which are able to perceive sun rays. Another factor gaining importance in obtaining visual elements close to reality in accordance with light is shadow. It is highly significant to superimpose shadows made by the virtual objects in 3D environments on the base they are standing visually with the required conditions in terms of objects in the given environment. That's why; it should also be considered that the shadows occurring virtually are indeed constructing two-dimensional visual elements in the augmented spaces. As in the dance choreography sample, producing the shadow's direction created by a virtual dancer in accordance with light conditions will considerably hinder the reality anxiety of the person.

Another parameter used to reinforce the reality perception is sound. Sound could be considered as a less problematic phenomenon in augmenting compared to visuals. When our emotional perception is oriented to the sounds of an environment, it attempts to understand the change by increased awareness. When augmenting the sound, real sounds are mixed with the added sounds in the same auditory space. However; adaptation of the spatialization character into the soundscape to be added is required to be able to make a sound compliance.

Rämö et al propose a model which can manipulate the transparent structure of sounds obtained by a binaural microphone in Augmented Reality earphone. Cohen et al present a study aiming at increasing navigation and situation awareness by producing a location based application with the proposed augmented audio reality. Subject of Augmented Sound Reality is very significant for Augmented Reality and it needs to be widely addressed. It is a positive factor for the sense of reality that the sounds of augmented virtual characters or objects are experienced in the environment of possible interactions. In order to achieve this, it is necessary to apply some spatialization methods on virtual voice source.

\section{RELATED WORKS ON AUGMENTATION REFINEMENTS}

There are still ongoing studies on some methods to compensate the differences between the spatial properties and visual qualifications such as the character and shadow of the light reflected and created respectively by the augmented object as well as the perspective of this object, which result from the Transparent and Framed Augmented Reality methods. The results of these research projects developing special methods for this augmentation situation help in understanding the complex structure of the topic. While proposing a Depth-Aware method, Hennessey et al recommend an image degradation process by adding 2D static images into existing 2D composition. Moreover, through this method, they provide augmentation related to the occlusion states of the objects by image segmentation. Kan et al conduct a blurring process of the augmented objects in compliance with the

Research Article - Submit Date: 15.11.2018, Acceptance Date: 15.12.2018 
lens detecting display area by an image processing method including depth-of-field information. Thus, stating that augmentation effect turns into a more realistic image, they could manage to soften the obvious sharpness of the $3 \mathrm{D}$ objects in terms of clarity.

Fischer et al proposed the softening of the transition from object to the background by applying antialiasing methods in the pixels where the augmented objects and the background coincide. Moreover, they tried to increase realism by adding a motion blur effect to the objects in case of any camera movement. As a result of the developments and enhancements in the display quality of the cameras used for getting images by time, there will be no need for the superfine image qualities of the added objects' to be exposed to degradation. However; many visual factors such as shadow controls, perception analysis related to motion and light characteristics will still be particular subjects to be studied in order to increase the augmented reality. One of the problems faced in reality perception increased through the interaction of virtual and real objects is the occlusion problem. In order to supply the possible interactions between augmented objects without physical substantial properties and existing objects, scenarios are to be evaluated in virtual space and the results are to be applied in a virtual environment after being computed in a congregated space.

\section{Z-DEPTH OCCLUSION PROBLEM ON FRAMED AUGMENTED REALITY EXPERIENCES}

Commonly, feature detection algorithms based on various image-processing techniques were recently applied in order to calculate the perspective information of the environment in Augmented Reality applications. Related to the obtained perspective information, augmented objects are settled into the image field orderly with the dynamically calculated transformations. When using RGB only cameras, 3D depth information of the environment cannot be investigated because the images obtained from RGB cameras are turned into RGBA information as pixels in a two-dimensional image matrix representation. However, 3D representation of the reflecting image from the camera is possible with the use of depth sensing cameras. Various investigations and applications about this subject can be performed with the use of the sensor-fitted cameras such as Kinect, Xtion named as RGB-D and equipped with an infrared perception system and an infrared projection system which is gaining popularity especially on the market. Infrared light patterns spreading the environment by infrared projectors are interpreted by the infrared cameras and hence, their pixel based depth information can be obtained.

Non-actual augmented elements by Framed Augmented Reality technique functions are located on the z-dimension of the real image obtained with the help of RGB cameras. Even if the added elements to the environment are located in compliance with the perspective condition of the obtained image field, their realities are considerably questioned due to the fact that they cannot show the front-back depth relation with the real elements in the environment visually.

Fig. 5: Framed Augmented Reality Z-Depth Problem

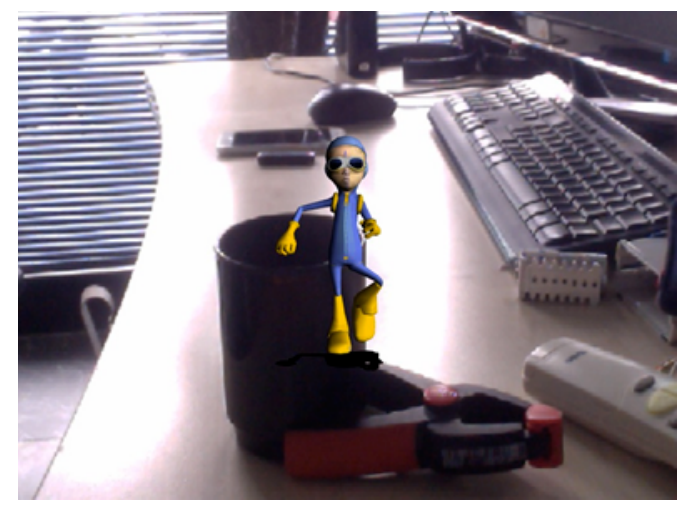

Research Article - Submit Date: 15.11.2018, Acceptance Date: 15.12.2018

DOI NO: 10.17932/IAU.EJNM.25480200.2019.3/1.45-56

Copyright (C) e-Journal of New Media 


\section{RELATED WORKS}

Some studies aimed at creating visual compositions according to z-depth information about Augmented Reality are conducted in various fields of computer sciences. Included in this particular field of study are the various methods such as: segregation of the objects by various image processing methods and determining the depth, segregation of the moving objects by the background and foreground image processing analysis, reconstruction of the environments in a 3D space by the cameras and sensors (which are able to determine depth information), and determining ordering relations. In their study Lepetit and Beger (2000) present a project which can perform the segregation automatically and make augmented objects both in the front and back through the segregation of the objects standing on the screen by drawing contours manually. Following the Layered Graph Cut algorithm applied by Kolmogorov et al, Ventura et al (2008) could make a human hand image both at the front and the back side of an augmented object thanks to the background-foreground analysis obtained through using color histogram methods. Kamat et al (2011) reformed the real and virtual objects in OpenGL Frame Buffer obtaining 3D information of the environment with depth buffer by using Time-of-Flight (TOF) cameras. However; obtained real image is presented as 3D scanned mesh geometry.

\section{IMPLEMENTATION}

Information of virtual objects' location whether at the front or back of the z-axis is required for the occlusion problem occurring related to the real and unreal interactions probably to be occurred in Augmented Reality environments. While virtual objects are moving in compliance with a coordinate system that could be used as reference in a 3D space setting, they would create occlusion situations with the real objects.

In this study, in order to overcome the occlusion problem specifically in Framed Augmented Reality, z-depth perceiving RGB-D cameras based on the infrared camera principle are used due to the fact that depth information at the region of interest is required. Beside the color values of the pixels, depth information can also be obtained thanks to the used Kinect Sensor. Thus, RGB and Depth data can be used for a specific resolution to perceive and describe a 3D environment.

Openframeworks based $\mathrm{C}++$ programming environment and OpenCV libraries are used for the production of the prototype software. Data obtained from depth buffering by using Kinect sensor are processed as Gray Image with a method through which the distance values turned into grey colors. Persons or objects standing in determined near and far threshold borders are separated from both back and the front planes by applying a pass filter. Filtered gray image is utilized in order to apply alpha masking to the original RGB image by using GLSL shader technique. Thus, information of a physical element included in the defined depth borders at the front or at the back related to an object augmented into the stage by layers may be comparable. A person or an object appearing between the minimum and maximum threshold distances is separated from the ground by masking and thus, image field can be recreated as three layers, which are AR, content, and person. The locations of the obtained layers are as follows: RGB image at the bottom, masked person and AR object at the up front. Entering the determined minimum and maximum depth borders, it enables the person to stand in front of the AR object with the mask. 
Fig. 6: Depth Order: (a) Camera View (b) Layered Augmented Object (c) Alpha Transparent Masked Image (d) Composition

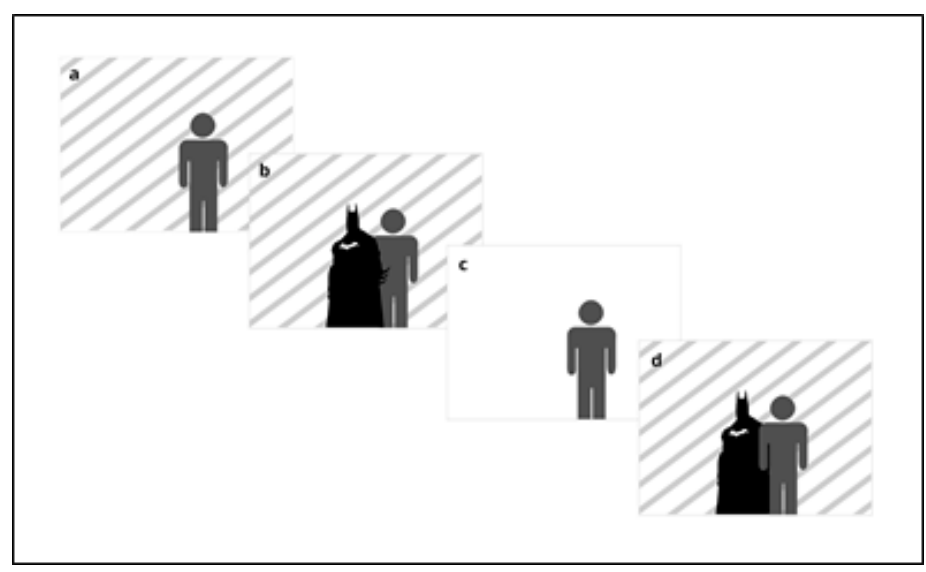

Fig. 7: Implementation Results: (Left) Actual image behind and in front of the AR image, (Right) Actual image in front of the AR image
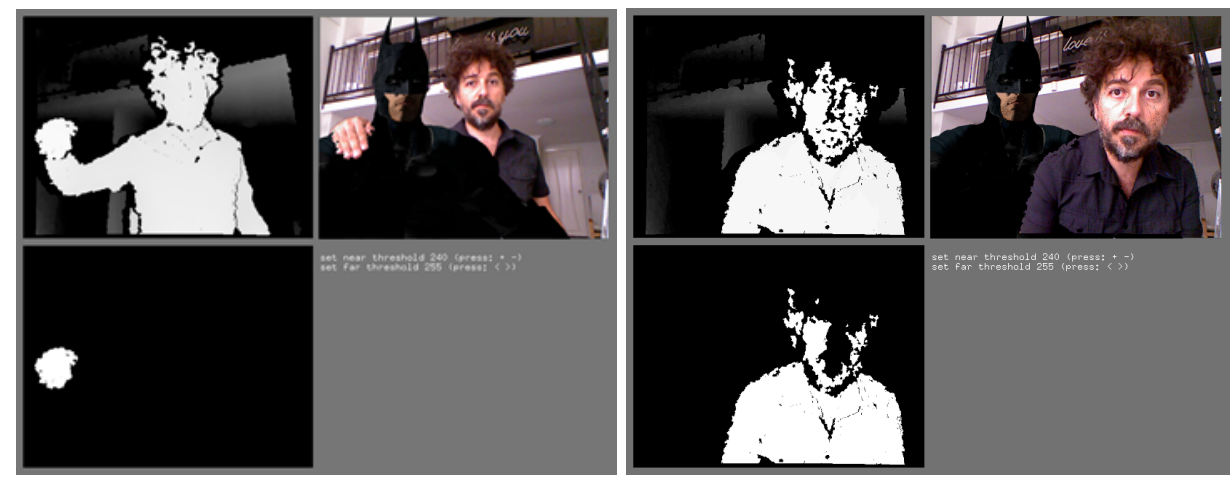

\section{PRACTICAL IMPLEMENTATIONS AND DISCUSSIONS}

The depth camera based segmentation method mentioned in this article is possible to be used in many Augmented Reality visual applications. For instance; it could be used in increasing the feeling of depth which can enable the occurrence of the reality illusion in terms of virtual characters or objects' interactions between the actor at the projection methods of dance and performance arts presenting special conditions. While virtual augmented actors move in accordance with the previously determined locations, real actors can perform their choreographies to make interactions through the marked information on the stage. Compliance of the virtual and real characters can be taken under control by supplying a location in a virtual environment prepared for an application developed for the dance performance. Simultaneous location information of the virtual actor can be reflected to the surface by a projection method supplied from a higher point in order for the actor to be able to follow the marking points. Thus, as stated in this article, the actor can appear whether in the front or back variant of the moving virtual object when the limiting of the minimum and maximum depth are stable. In a study following this one, the minimum and maximum depth could be dynamically varying. Another development to be made in the further phases of this conducted study is the simultaneous animation of the virtual character if there is a 3D biped built body structure. There have been some studies conducted on augmenting biped characters in space (Yoon et al 2013, Vera et al 2011, Sinthanayothin et al 2012, Aitpayev et al 2012). The depth camera based segmentation method proposed in this study could be implemented to solve some of the occlusion problems of 3D augmented avatars.

Research Article - Submit Date: 15.11.2018, Acceptance Date: 15.12.2018 


\section{CONCLUSION}

The association between unreal and real offered by Augmented Reality to humanity provides new opportunities to our rapidly changing and developing visual perceptions. Now being integrated into our technological lives with the use of different applications, Augmented Reality is a phenomenon which is required to be properly categorized into different scenarios and deeply understood. It is aimed in this article to classify what kind of a technological metamorphosis the reality notion has been going through. Augmented Reality applications which have recently become widespread, are subcategorized and some of the definitions are scrutinized. Connecting the real and unreal is a technically challenging issue.

Different enhancing methods applied to increase the reality in mentioned augmented reality scenarios are investigated. Thanks to the segmentation applied with the RGB-D masking method proposed for the occlusion problem occurring as a consequence of the interactions of virtual and real objects, ordering relation at the z-axis between the objects fictionalized, is under control. Thus, while an augmented object can sometimes occur in front of the real object, it can also sometimes be behind. Increase of the reality sense attempted to be attained by Augmented Reality is only possible after solving problems caused by occlusion state.

With the implementation of mixed reality techniques, the anxiety levels of being placed in an artificial environment could be lowered and the users of such systems would be keen to participate in such interactive situations. Advancements in computational power for the use of real time interactive systems are enhancing and this accelerated move permits the researchers and developers to create superreal environments with outstanding features. Game industry has been celebrating new approaching advancements in computer graphics technologies, but we would need to also include fields of interests such as educational platforms, artistic projects and medical implementations.

RGB-D Cameras are becoming widely used for end custmers in the forms of gaming consoles and mobile devices. Efficient integration of multiple camera processing with the inclusion of infra-red based depth data provides extensive opportunities for creating realistic augmented reality scenarios. As it has been widely discussed in this paper, occlusion problem has been standing as a major obstacle to overcome the affirmation of placing rendered elements into real environments. Further studies in the rendering conditions such as the use of proper lighting techniques, shadowing and texturing will improve the use of RGB-D systems in providing convincing results.

\section{REFERENCES}

Aitpayev, K., \& Gaber. (2012), J. Creation of 3D human avatar using kinect. Asian Transactions on Fundamentals of Electronics, Communication \& Multimedia, 1(5), pp.12-24.

Azuma. (1997), R. T. A survey of augmented reality. Presence: Teleoperators \& Virtual Environments, 6(4), pp 355-385.

Bodnar, J. L., Candoré, J. C., Nicolas, J. L., Szatanik, G., Detalle, V., \& Vallet, J. M. (2012) Stimulated infrared thermography applied to help restoring mural paintings. Ndt \& E International, 49,pp 40-46.

Brooker, J. (2007), The polytechnic ghost: Pepper's ghost, metempsychosis and the magic lantern at the royal polytechnic institution. Early Popular Visual Culture, 5(2), pp 189-206.

Elmorshidy, A. (2010), Holographic Projection Technology: The World is Changing. Journal of Telecommunications, Vol.2 Issue 2.

Fischer, J., Bartz, D. (2006), \& Straser, W. Enhanced visual realism by incorporating camera image effects. In Proceedings of the 5th IEEE and ACM International Symposium on Mixed and Augmented Reality, October. pp. 205-208. IEEE Computer Society. 
Henderson, L. D. (1988), X Rays and the Quest for Invisible Reality in the Art of Kupka, Duchamp, and the Cubists. Art Journal Vol. 47, Iss. 4.

Hennessey, J. W., \& Mitra, N. J. (2015), August. An Image Degradation Model for Depth augmented Image Editing. In Computer Graphics Forum, Vol. 34, No. 5, pp. 191-199.

https://www.youtube.com/watch? $v=$ DoojxzS1fCw (Retrived 20.08.2015)

J.C. Candore, J.L. Bodnar, V. Detalle and P. Grossel. (2012), Non-destructive testing of works of art by stimulated infrared thermography. The European Physical Journal Applied Physics, 57, 21002 doi:10.1051/epjap/2011110266

Kamat, V. R., \& Dong, S. (1901), Resolving incorrect visual occlusion in outdoor augmented reality using TOF camera and OpenGL frame buffer. Proceedings of NSF, 2011, pp 1-8.

Kamphius, Carolinen, Esther Barsom, Marlies Sschijven, and Noor Christoph. (2014), Augmented Reality In Medical Education?. Perspect Med Educ 3 (4): pp 300-311.

Kan, P. \& Kaufmann, H. (2012), Physically-Based Depth of Field in Augmented Reality. In Eurographics (Short Papers), pp. 89-92.

Kaufmann, Hannes, and Dieter Schmalstieg. (2003), Mathematics and Geometry Education With Collaborative Augmented Reality. Computers \& Graphics 27 (3): pp 339-345.

Kolmogorov, V., Criminisi, A., Blake, A., Cross, G., \& Rother, C, June. (2005), Bi-layer segmentation of binocular stereo video. In Computer Vision and Pattern Recognition. CVPR 2005. IEEE Computer Society Conference, 2005, Vol. 2, pp. 407-414.

Kuhn, G., Amlani, Alym A. \& Rensink, Ronal A. (2008), Towards a Science of Magic. Trends in Cognitive Sciences 12.9, 349-354

Lepetit, V., \& Berger, M. O. (2000), A semi-automatic method for resolving occlusion in augmented reality. In Computer Vision and Pattern Recognition, 2000. Proceedings. IEEE Conference, Vol. 2, pp. 225-230.

Lindberg, David C. (2010), Theories of Vision from Al-Kindi to Kepler. University of Chicago Press McGinnis, Jon. Avicenna. (1981), Oxford University Press.

Pal G.K., Pal. P. (2001), Textbook of Practical Physiology. Sangam Books Ltd.

Ramö, J., \& Valimaki, V. (2012), Digital Augmented Reality Audio Headset. Journal of Electrical and Computer Engineering.

Rowe, A. (2014), Designing for engagement in mixed reality experiences that combine projection mapping and camera-based interaction. Digital Creativity, 25(2), pp 155-168.

Schweitzer, M. (2014), \& Zerdy, J. Performing Objects and Theatrical Things. Palgrave Macmillan.

Sidharta, R., Hiyama, A., Tanikawa , T., \& Hirose, M. (2006), The Development of Multi-Depth Pepper's Ghost Display for Mixed Reality System. Proceedings of the 16th International Conference on Artificial Reality and Telexistence--Workshops (ICAT'06).

Sinthanayothin, C., Wongwaen, N., \& Bholsithi, W. (2012), Skeleton Tracking using Kinect Sensor \& Displaying in $3 D$ Virtual Scene. International Journal of Advancements in Computing Technology, 4(11).

Tsuji, Shigeru. (1990), Brunelleschi and the Camera Obscura: The Discovery of Pictoral Perspective. Art History 13-3: pp 276-292.

Ventura, J., \& Höllerer, T, August. (2008), Depth compositing for augmented reality. In SIGGRAPH posters, p. 64.

Vera, L., Gimeno, J., Coma, I., \& Fernandez, M. (2011), Augmented mirror: interactive augmented reality system based on kinect. In Human-Computer Interaction-INTERACT 2011, Springer Berlin Heidelberg, pp. 483-486.

Yoh, Myeung-Sook. (2011), The Reality of Virtual Reality. Proceedings of the Seventh International Conference on Virtual Systems and Multimedia (VSMM'01).

Yoon, H. C., \& Park, J. S. (2013), Avatar animation using skeleton tracking with Kinect sensor. International Journal of Advancements in Computing Technology, 5(12), p.339. 